\title{
Src/tubulin Inhibitor KX02
}

National Cancer Institute

\section{Source}

National Cancer Institute. Src/tubulin Inhibitor KX02. NCI Thesaurus. Code C120101.

A lipophilic, orally available inhibitor of both Src kinase activity and tubulin polymerization, with potential antineoplastic activity. Upon oral administration, src/tubulin inhibitor KX02 binds to and inhibits the activity of Src kinase. This inhibits both downstream signaling and the proliferation of Src kinase-expressing tumor cells. KX02 also binds to tubulin heterodimers and inhibits microtubule polymerization, thereby disrupting microtubule formation, mitosis, and further proliferation. Src, a non-receptor tyrosine kinase, is overexpressed in a variety of tumor cell types and plays a key role in tumor cell proliferation, angiogenesis, migration, and metastasis. 